\title{
Evaluation of local anesthetic and antipyretic activities of Cinchona alkaloids in some animal models
}

\author{
Yan $\mathrm{Li}^{*}$ and Jun Tian \\ Department of Anaesthesiology, Xinxiang Central Hospital of Henan Province, 56 Jinsui Road, Xinxiang 453000, China
}

*For correspondence: Email: liyan0344@gmail.com; Tel/Fax: 0086-373-2022300

Received: 20 February 2016

Revised accepted: 18 July 2016

\begin{abstract}
Purpose: To evaluate the local anesthetic and antipyretic activities of an aqueous extract of Cinchona officinalis (C. officinalis) in experimental animal models.

Methods: Various doses of the aqueous extract was tested for its local anesthetic activity in guinea pigs and frogs using intracutaneous and plexus anesthesia, respectively. For comparison, $2 \%$ xylocaine was used as a reference drug. The anti-pyretic activity of the aqueous extract was determined by Brewer's yeast-induced pyrexia in rats, using aspirin $(300 \mathrm{mg} / \mathrm{kg})$ as reference.

Results: C. officinalis extract, at concentrations of 10 and $20 \%$, produced significant anesthetic effects, of 72.12 and $88.08 \%$, respectively, compared with $96.86 \%$ anesthetic effect of $2 \%$ standard xylocaine $(p<0.001)$. In the plexus model, the mean onset of anesthetic effect was recorded at $6.44 \pm 0.68 \mathrm{~min}$ versus $3.86 \pm 0.42 \mathrm{~min}(p<0.001)$ for the standard drug. Single administration of the extract $(100,200$ and $400 \mathrm{mg} / \mathrm{kg}$ ) showed significant dose-dependent anti-pyretic activity throughout the observation period, which was comparable to the standard aspirin group.

Conclusions: The findings suggest that the aqueous extract of $\mathrm{C}$. officinalis has significant local anesthetic and anti-pyretic activities in rats.
\end{abstract}

Keywords: Cinchona officinalis, Antipyretic, Aspirin, Local anesthesia, Cinchona alkaloids, Xylocaine

Tropical Journal of Pharmaceutical Research is indexed by Science Citation Index (SciSearch), Scopus, International Pharmaceutical Abstract, Chemical Abstracts, Embase, Index Copernicus, EBSCO, African Index Medicus, JournalSeek, Journal Citation Reports/Science Edition, Directory of Open Access Journals (DOAJ), African Journal Online, Bioline International, Open-J-Gate and Pharmacy Abstracts

\section{INTRODUCTION}

The use of medicinal plants in treating ailments has been an integral part of traditional medicine for centuries. Importantly, herbal medicines play a vital role in developed, as well as developing, countries in improving primary healthcare because of their effective biological and medicinal properties with high safety margins and low costs.

C. officinalis is one traditional medicinal plant, belonging to the family Rubiaceae. Its extracts are the main ingredient in Indian Ayurvedic formulations to treat various fever types, including malaria [1]. Apart from this, various peoples have used cinchona barks for different purposes as medicinal agents. In Brazilian medicine, it has been used as a digestive tract stimulant and fever reducer, while in South America generally, it is used to treat cancers, in Europe, cinchona extract has been used as an anti-protozoal and anti-spasmodic, and in the USA, it has been used as a digestive tonic, and as a treatment for cardiac disorders.

Basically, Cinchona alkaloids are abundantly present as organic molecules that have been isolated from the bark of about 40 species of cinchona trees around globe. The major chemical constituents of these alkaloids are quinine and quinidine; cinchonine and 
cinchonidine can also comprise up to $16 \%$ by mass of total tree bark. Nearly, most of these extracts have been utilized in the food and beverage industry as bitter additives. They have also been used as an important anti-malarial drug; as a muscle spasm relaxant agent; and as a cardiac depressant (anti-arrhythmic). Because of their increasing commercial importance, several cinchona species are now widely cultivated in various parts of the world $[2,3]$

In the present study, we evaluated the local anesthetic and anti-pyretic potential of an aqueous extract of $C$. officinalis. We used some animal models (guinea pig, frog and albino rat) in the experiments.

\section{EXPERIMENTAL}

\section{Materials}

Xylocaine, sodium chloride, Brewer's yeast, and acetyl salicylic acid were obtained from Sigma Aldrich and were used without further processing.

\section{Preparation of C. officinalis extract}

Fresh stem bark of Cinchona was collected from Western Ghats in Tamil Nadu, India, and authenticated in the Pharmacognosy and Phytochemistry Department of Agricultural University, Tamil Nadu, India with a voucher specimen (no. PEAR-PAA-06/14) preserved in the department's herbarium. The shade-dried stems were ground to a fine powder with a mechanical grinder, and $300 \mathrm{~g}$ of the pulverized powder material was extracted with doubledistilled water using a Soxhlet apparatus at $60^{\circ} \mathrm{C}$ for approximately $48 \mathrm{~h}$. The yield of the aqueous extract was $14.1 \%(\mathrm{w} / \mathrm{w})$ in the air-dried powder form, and it was stored in an air-tight container at $4{ }^{\circ} \mathrm{C}$ until used.

\section{Phytochemical studies}

The powdered aqueous extract was subjected to phytochemical screening analysis using fluorescence, thalleoquin, and Rosequin tests [4].

\section{Experimental animals}

Adult male guinea pigs weighing 300-400 g, frogs, and albino rats weighing $2.5-3 \mathrm{~kg}$, were procured from the central animal house of the Xinxiang Medical Institute. The animals were acclimatized to the laboratory atmosphere for 7 days prior to the experiment, at a controlled room temperature $\left(24 \pm 2{ }^{\circ} \mathrm{C}\right.$; relative humidity $60-70$ $\%)$ under a 12/12-h light-dark cycle. They were given a standard laboratory diet and water ad libitum. The experimental protocol was conducted after approval of the Institutional Animal Ethics Committee of Xinxiang Medical University (approval ref no. 2013/514B-21). The studies were performed in compliance with Directive 2010/63/EU on careful handling of animals for scientific purposes [5].

\section{Acute oral toxicity study}

An acute oral toxicity study was carried out using the aqueous extract $(0-2000 \mathrm{mg} / \mathrm{kg})$ and the acute toxicity method prescribed by the Organization of Economic Co-operation and Development (OECD) Guidelines (No. 423) [6].

\section{Evaluation of local anesthetic activity}

\section{Intradermal wheal guinea pig model}

Guinea pigs were shaved (four different areas of $4 \mathrm{~cm}^{2}$ each) and divided into four groups (Table 1). The normal response of the animals to a pin prick was tested with $0.2 \mathrm{ml}$ extract of $C$. officinalis $(50 \mathrm{mg})$ injected intradermally on the left side of the animal, with $0.2 \mathrm{ml}$ normal saline injected on the right. Six pin pricks were applied uniformly $5 \mathrm{~min}$ at an interval of $3-4 \mathrm{~s}$ on the wheal areas for up to $30 \mathrm{~min}$. A skin twitch, usually accompanied by a squeak, was considered as a normal response to the pin prick. Animals that failed to respond or produced no squeak response to all pin pricks were considered to show a positive response to the anesthetic effect $[7,8]$.

Table 1: Local anesthetic activity of aqueous extract on intracutaneous wheal in guinea pigs

\begin{tabular}{|c|c|c|c|}
\hline Group & Drug & $\begin{array}{c}\text { No. of } \\
\text { negative } \\
\text { responses }\end{array}$ & $\begin{array}{c}\text { Mean } \\
\text { failure of } \\
\text { response } \\
(\%)\end{array}$ \\
\hline$\overline{\mathrm{A} \text { (Control) }}$ & $0.9 \%$ saline & $1.7 \pm 0.84$ & 5.26 \\
\hline B (Test) & $10 \% A Q$ & $27.46 \pm 4.16^{*}$ & $72.12^{*}$ \\
\hline C (Test) & $20 \% A Q$ & $33.48 \pm 2.04^{*}$ & $88.08^{*}$ \\
\hline D (Standard) & $2 \%$ xylocaine & $37.12 \pm 0.68^{*}$ & $96.86^{*}$ \\
\hline $\begin{array}{l}A Q=\text { Aqueou } \\
\text { each group }\end{array}$ & & & \\
\hline
\end{tabular}

\section{Plexus anesthesia in frog model}

Frogs were divided into three groups (Table 2). They were pitched and the upper part of the spinal cord was destroyed. Four limbs were nailed on the frog board and a transverse incision was made on the abdominal wall just below the sternum. The viscera were removed carefully through this opening and the lumbar plexus was exposed carefully without damaging 
it. Then, the abdominal pouch was filled with 20 $\%$ of the extract as a test drug. Reflex activity was noted by immersing the left and right limbs of the frog, every $2 \mathrm{~min}$ for up to $10 \mathrm{~s}$, into $0.01 \mathrm{~N}$ $\mathrm{HCl}$ and normal saline, respectively. The time taken for the disappearance of reflex activity in the feet was recorded and the time of onset of local anesthetic action was calculated [8-12].

Table 2: Local anesthetic activity of aqueous extract on plexus of frog

\begin{tabular}{lcc}
\hline Group & Drug & $\begin{array}{c}\text { Onset of } \\
\text { anesthetic action } \\
(\text { mean } \pm \text { SEM) } \\
(\mathbf{m i n})\end{array}$ \\
\hline $\mathrm{A}$ (Control) & $0.9 \%$ saline & $25.27 \pm 1.65$ \\
$\mathrm{~B}$ (Test) & $20 \% \mathrm{AQ}$ & $6.44 \pm 0.68^{*}$ \\
$\mathrm{C}$ (Standard) & $2 \%$ xylocaine & $3.86 \pm 0.42^{*}$ \\
\hline AQ = aqueous extract; ${ }^{*} P<0.001$, vs. control. $n=6$ in \\
\multicolumn{2}{l}{ each group }
\end{tabular}

\section{Evaluation of antipyretic activity}

Rats were divided into five groups. Fever was induced by subcutaneous injection of $20 \mathrm{mg} / \mathrm{kg}$ of a $20 \%$ normal saline suspension of Brewer's yeast below the nape of the neck. Initial rectal temperature was recorded and, after $18 \mathrm{~h}$, animals showing a temperature difference of $0.3-0.5{ }^{\circ} \mathrm{C}$ were selected. The control group $(\mathrm{A})$ received vehicle (1\% Tween 80$)$, the standard group (E) received aspirin $150 \mathrm{mg} / \mathrm{kg}$, and groups $B, C$, and $D$ received 100,250 , and 500 $\mathrm{mg} / \mathrm{kg}$ of the aqueous extract (po), respectively. Variation in rectal temperature was recorded at different time intervals [13-15].

\section{Statistical analysis}

Statistical analysis was carried out by one-way ANOVA followed by Dunnett's multiple $t$ test. $P<$ 0.05 was considered to indicate statistical significance. GraphPad Prism5 software (GraphPad Software, Inc, La Jolla, CA, USA) was used to perform the analysis.

\section{RESULTS}

The aqueous extract of $C$. officinalis showed blue fluorescence and unique colors in each test, suggesting the presence of alkaloids, tannins, flavonoids, phenolic compounds, and triterpenes [16]. The aqueous extract, tested at up to 2000 $\mathrm{mg} / \mathrm{kg}$, was found to be non-toxic (category 5 according to the OECD guidelines).

The local anesthetic activity results of the samples in the guinea pig wheal test are presented in Table 1, which shows that the extract at $20 \%$ concentration produced $88.08 \%$, and that at $10 \%$ concentration produced 72.12 $\%$ anesthetic activity; in contrast, the standard xylocaine showed $96.86 \%$ activity. The extract of C. officinalis was significant versus the control group $[17,18]$.

Table 2 shows the activity of the aqueous extract on plexus anesthesia in the frog model. The mean onset of anesthetic action for $20 \%$ aqueous extract was $6.44 \pm 0.68 \mathrm{~min}$ versus 3.86 $\pm 0.42 \mathrm{~min}$ for the standard drug xylocaine. Compared with the control group (saline), the 20 $\%$ aqueous extract showed a significant difference in anesthetic action.

The results of the anti-pyretic effects of the control, standard drug (aspirin), and aqueous extract (at doses of 100, 250, and $500 \mathrm{mg} / \mathrm{kg}$ ) are shown in Figure 1. Aspirin and the extract at 250 and $500 \mathrm{mg} / \mathrm{kg}$ started to show significant reduction in body temperature at $1 \mathrm{~h}$ post-dosing compared with the control group. The anti-pyretic action was sustained for up to $3 \mathrm{~h}$ after aspirin and aqueous extract administration [19,20].

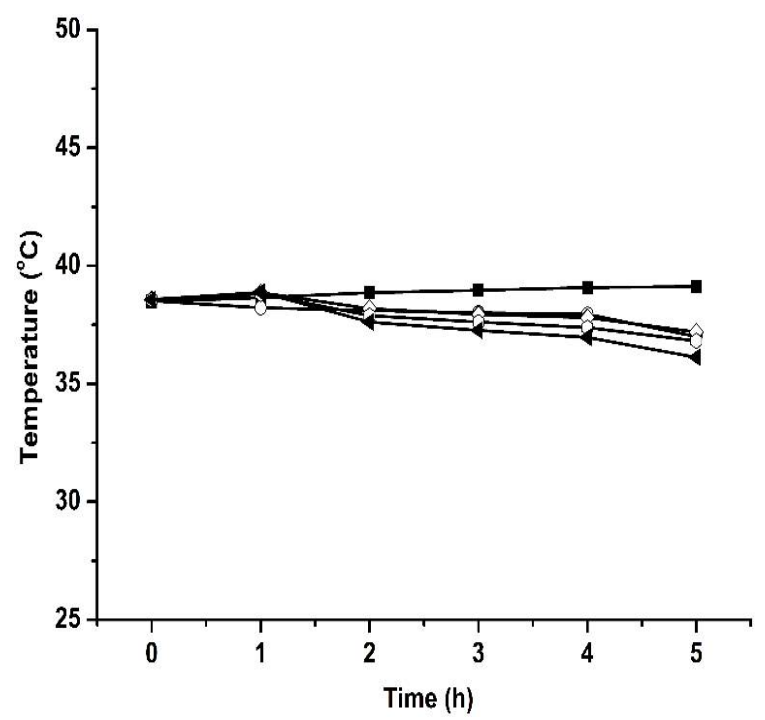

Figure 1: Anti-pyretic activity of C.officinalis extract in albino rats. Closed square, Group A; open circle, Group B; open square, Group C; open circle, Group D; and closed rectangle, Group E

\section{DISCUSSION}

A comparative study of the local anesthetic activity of a natural plant extract was made in two animal species, guinea pigs and frogs. The aqueous extract of $C$. officinalis showed local anesthetic activity following intradermal injection in guinea pigs. Plant extract produced rapid dose-dependent local anesthesia in the wheal model. The results suggest that the extract was 
able to inhibit nerve impulse conduction in the skin of guinea pigs. The $C$. officinalis extract also produced statistically significant rapid plexus anesthesia in the frog model. The onset of the local anesthetic effect with the aqueous extract was almost equal to that of the standard drug. This was consistent with previous reports.

Basically, most of the anti-inflammatory drugs possess anti-pyretic effect. Here, the tested $C$. officinalis extract markedly reduced the rectal temperature of pyretic rats. This indicated antipyretic activity of the extract in the yeast-induced rats, possibly because the production of prostaglandins was suppressed by the chemical constituents of the plant extract, which is responsible for fever induction in the central nervous system (CNS). Indeed, the flavonoid content in $C$. officinalis may be responsible for its anti-pyretic activity, by inhibiting prostaglandin synthesis in the hypothalamus.

\section{CONCLUSION}

In conclusion, the present study showed that an aqueous extract of plant $C$. officinalis had local anesthetic and anti-pyretic activity in guinea pigs, frogs, and rats. Because this is a preliminary report, further studies are needed to analyze the possible mechanisms of action.

\section{DECLARATIONS}

\section{Acknowledgement}

The authors thank the staff of the Department of Anesthesiology, Xinxiang Central Hospital, Henan Province for their support.

\section{Conflict of Interest}

No conflict of interest associated with this work.

\section{Contribution of Authors}

The authors declare that this work was done by the authors named in this article and all liabilities pertaining to claims relating to the content of this article will be borne by them.

\section{REFERENCES}

1. Bohórquez E, Chua M, Meshnick SR. Quinine localizes to a non-acidic compartment within the food vacuole of the malaria parasite Plasmodium falciparum. Malaria $J$ 2012; 11: 350.

2. Nadkarni KM. Indian Materia Medica. Popular Prakashan Pvt. Ltd., Mumbai: 1976; 1163-1164.
3. Kokate CK. Plant constituents. Practical pharmacognosy. Vallabh Prakashan (ed). Delhi: 1977; 230-236.

4. Gill LS, Idu M, Ogbor DN. Folk Medicinal plants: Practice and beliefs of the Bini people in Nigeria. Ethnobot 1997; 9: 1-5.

5. European Commission [homepage on the internet]. Directive 2010/63/EU on the protection of animals used for scientific purposes [cited 2015 June 11]. Available from:

http://ec.europa.eu/environment/chemicals/lab_animals/l egislation_en.htm

6. Boruah RN, Leclercq PA. Characterisation of the essential oil from flower heads of Spilanthes acmella. J Essential Oil Res 1993; 5: 693-695.

7. Ghosh MN. Toxicity studies. Fundamentals of Experimental Pharmacology. Scientific Book Agency. Calcutta: 1984; 153-158.

8. Bulbring E, Wajda I. Biological comparison of local anaesthetics. J Pharmacol 1945; 85: 78-84.

9. Sheth SD.; Maulik MG. Drugs acting on CNS. B.I. Churchill Livingstone Pvt. Ltd; New Delhi. 1999; 424430.

10. Lahon LC, Khanikor HN, Ahmed N. Preliminary study of local anaesthetic activity of Euphorbia nerifoliaLinn. Indian J Pharmacol 1979; 11:239-240.

11. Kalra NA, Bhatt RV, Trivedi U, Trivedi JJ, Goyal RK. Local anaesthetic activity of some basic amide compounds. Indian J Pharmacol 1993; 25: 30-33.

12. Liu SS. Local anesthetic. In: Michael AA, Linda JR, Editors. The Management of Pain. Churchill Livingstone Inc.; USA: 1998; 447-448.

13. Burn JH, Finney DJ, Goodwin LG. Local anaesthetics. Biological standardization. Geoffrey Cumberlege; London: 1952; 325-331.

14. Agshikar NV, Abraham GJ. Pharmacology and acute toxicity of essential oil extracted from Zanthoxylum budrunga. Indian J Med Res 1972; 60: 757-761.

15. Burn JH, Finney DJ, Goodwin LG. Antipyretic and analgesics. Biological standardization. Geoffrey Cumberlege; London: 1952; 311-319.

16. Gupta MB, Palit TK, Singh $N$, Bhargava KP. Pharmacological studies to isolate the active constituents from Cyperus rotundus possessing antiinflammatory, antipyretic and analgesic activities. Indian J Med Res 1971; 59: 76-82.

17. Mukherjee PK, Das J, Saha K, Giri SN, Pal M, Saha BP. Antipyretic activity of Nelumbo nuciferarhizome extract, Indian J Exp Biol 1996; 34: 275-276.

18. Trease GE, Evans WC. Phenolic compounds and tannins. Pharmacognosy. Bailliere Trindall; London: 1972; 146-148.

19. Rajnarayana K, Reddy MS, Chaluvadi MR, Krishna DR. Bioflavonoids classification, pharmacological, biochemical effects and therapeutic potential. Indian J Pharmacol 2001; 33: 2-16.

20. Walle T, Browning AM, Steed LL, Reed SG, Walle UK. Flavonoid glucosides are hydrolyzed and thus activated in the oral cavity in humans. J Nutr 2005; 135: 48-52.

Trop J Pharm Res, August 2016; 15(8): 1666 